\title{
Novae quaedam Fulgorinorum formae speciesque insigniores
}

\author{
descriptae \\ Carolo $\mathbf{S} t$ å $l$.
}

\section{Enchophora Spin.}

1. E. obtusiceps. Capite obtuso, testacea, subtus cum pedibus flavotestacea, fronte nigrosparsa; pedibus nigro-annulatis; clypeo macula oblonga media nigrofusca; clavo pellucido, griseo, fusconebuloso, corii dimidio basali testaceo, fusco-nebuloso, dimidio apicali alisque vitreis, illo fusco-sparso, his basin versus pallide flavovirescente-hyalinis; abdomine supra nigro, segmentis apice olivaceolimbatis. - Long. corp. 14, Exp. al. 37 Millim.

Patria: Brasilia. Mus. Berol.

Caput ante oculos parum prominens, obtusum, vertice transverso, apice sinuato, antrorsum angustato; fronte latitudine media sublongiore, infra medium utrimque rotundato-ampliata, retrorsum vix sinuato-angustata, basi convexo-reflexa, et, uti videtur, in sinu anticỏ verticis inflexa, carinis 2 obtusis instructa. Thorax postice truncatus, scutello vix tertia parte brevior. Tegmina latitudine media plus ter longiora.

\section{Glagơvia Stål.}

Caput thorace paullo angustius, obtuse rotundatum, vertice brevi, transversim parallelo; fronte convexa, laevi, longitudine nonnihil latiore, ante antennas utrimque leviter sinuata. Thorax vertice nonnihil longior, scutello dimidio brevior. Tegmina parallela, abdomen superantia. Pedes simplices, tibiis posticis quadrispinosis.

Omalocephalae affine genus, capite aliter formato.

1. G. bella. Olivaceo-viridis, nitida; scutello pectoreque sordide flavo-testaceis; tegminibus fuscis, maculis flavis viridi-cinctis ornatis, limbo costali viridi, maculis flavis, nigrocinctis notato, 
parte tertia apicali nigra, testaceo-fasciata; alis testaceo-flavescentibus, limbo posteriore parteque apicali nigrofuscis; pedibus nigrofuscis, posticis flavo-testaceis. - Long. 15, Exp. al. 38 Millim.

Patria: Zangibar. Coll. Stål.

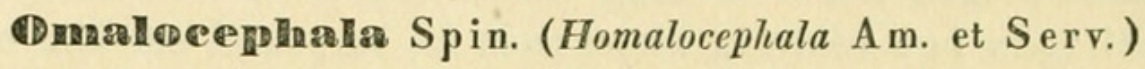

1. O. carinifrons. Viridi-olivacea; macula utrimque basali scutelli, pectore, ventre, pedibus discoque clypei sordide flavo-albidis; tegminibus lutescentibus, apicem versus dilute sordide flavescentibus, olivaceo-nigro-maculatis, limbo costali viridi-olivacen, nigromaculato; alis sanguineis, limbo postico areaque apicali nigro-fuscis; abdomine supra nigro, parte dimidia apicali lutea, disco nigro. - Long. 16, Exp. al. 40 Millim.

Patria: Caffraria. Mus. Berol.

Caput valde triangulariter productum, thorace duplo longius, vertice latitudine basali nonnihil longiore, tricarinato, carinis media percurrente, lateralibus antrorsum convergentibus, apice evanescentibus; genis nonnihil pone verticis apicem terminatis; fronte ante verticem nonnihil prominente, latitudine vix duplo longiore, dimidio supero sursum sensim angustato, apice rotundato, dimidio infero parallelo, supra clypeum utrimque paullo ampliato, quinque-carinata, carinis versus elypeum evanescentibus.

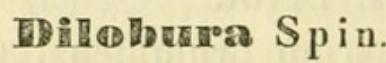

1. D. verrucosa. Subvirescente-albida, alis albidis; tegminibus parce tuberculatis, margine costali pone medium distincte sinuato, maculis 2 parvis subbasalibus corii serieque abbreviata macularum parvarum clavi ad suturam clavi, maculis clypei femorumgue anticorum ventreque (excepto margine apicali segmentorum) nigris; tibiis omnibus extus leviter dilatatis. - Long. 17, Exp. al. 60 Millim.

Patria: Rio Janeiro. Mus. Berol.

Caput obtusum, vertice transverso, medio quam utrimque haud longiore, subparallelo; fronte subparallela, utrimque leviter sinuata, longitudine dimidio latiore, basi quam latissime rotundata, carinis tribus subundatis. Thorax posterius et scutellum anterius conjunctim convexa, ille posterius carinula, inter medium et latera tuberculo instructus; hoc posterius depressum, pone tubercula thoracis tuberculis etiam instructum. Tegmina ampla, latitudine duplo longiora, pone medium distincte sinuata, margine ipso maculis miputis fuscis notato. Tibiae posticae quinquespinosae. 
2. D. tosta. Fusco-favescens, subtus dilutior, pedibus fuscosparsis et subannulatis; tegminibus alisque sordide hyalinis, fuscovenosis, illis ante medium pallide flavescente-nebulosis maculisque 2 flavescentibus apicem versus ornatis. - Long. 20, Exp. al. 51 Millim.

Patria: Surinam. Mus. Berol.

Caput antice obtuse rotundatum, ante oculos multo prominens; vertice semilunato, basi late sinuato, antice subsemicirculariter rotundato, longitudine media vix duplo et dimidio latiore, supra oculos leviter angulato-ampliato et subreflexo; fronte latitudine basali paullo longiore, basi late rotundata, ante verticem subprominula, angulis basalibus rectis, libere prominentibus, apicem versus leviter angustata, medio utrimque nonnihil sinuata, carinis 2 percurrentibus approximatis, basin et apicem versus convergentibus, nec non carinulis 3 abbreviatis ante medium, una fortiore inter carinas laterales, 2 aliis lateralibus. Tegmina latitudine duplo et dimidio longiora, margine costali pone medium leviter sinuato. Tibiae anteriores haud dilatatae; posticae subdilatatae, quadrispinosae.

3. D. conspurcata. Grisea, alis albidis; capite ante oculos vix prominulo, supra viso transverso; punctis 4 anticis et 2 basalibus verticis, litura genarum ante oculos, linea transversa basali, punctis 2 lineolaque utrimque transversa infra medium frontis transversim positis, linea transversa basali scutelli, punctis raris marginis costalis tegminum maculisque exterioribus tibiarum nigris; venis tegminum hic illic minute fusco-indutis. - Long. 17, Exp. al. 48 Millim.

Patria: Cametà. Mus. Berol.

D. Spinolae Am. et Serv. (= corticinae Spin.) affinis, capite supra viso breviore, antice late rotundato, vertice medio quam utrimque vix longiore; fronte longitudine nonnihil latiore, basi late rotundata, a basi ultra medium sensim leviter ampliata. Thorax vertice fere dimidio longior, scutello vix dimidio brevior, laeviusculus, non nisi subtilissime rugulosus. Scutellum laeve.

4. D. atro-annulata. Virescente-vel flavescente-grisea,verticis lineis 2 undulatis, antrorsum divergentibus, fascia subbasali irregulari liturisque subapicalibus frontis, impressionibus 2 parvis thoracis, maculis scutelli pectorisque parvis, annulis fasciisque pedum nigris; tegminibus nigro-irroratis et sparsis; abdominis dorso alisque dilute lutescentibus, venis primariis harum areaque apicali nigrofuscis. - Long. 14, Exp. al. 40 Millim.

Patria: Brasilia. Mus. Berol.

D. conspurcatae proxima, vertice medio quam utrimque 
distincte longiore; fronte parallela, longitudine parum latiore. Tegmina latitudine media plus duplo et dimidio, vix ter longiora.

\section{Cyrene Westw.}

1. C. foliacea. Sordide favo-testacea, processu capilis apice nigro-fusco; tegminibus nitidis, olivaceo-flavescentibus, viridi-veno-

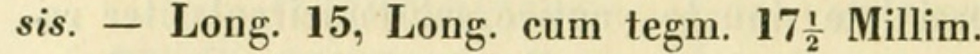

Patria: Bintam. Mus. Berol.

Caput conico - protuberans, thorace cum scutello nonnihil longius, apice acute spinoso-terminatum. Thorax parce subfortiter punctatus. Tegmina nitida, granulato-rugulosa, corii parte dimidia basali (excepto ad suturam clavi) laevissima, angulo apicali commisurali spinula terminato.

Prseudopleana Burm.

1. P. validicornis. Capite longissimo, fusco-testacea; clypeo, pedibus abdomineque testaceo-albidis, tegminibus vitreis, apicem

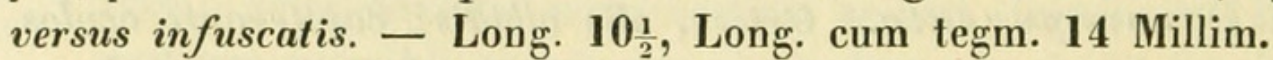

Patria: Andalusia. D. Staudinger. Mus. Berol.

Caput corpori reliquo aequilongum, protuberantia cylindrica, aequicrassa, laevissime subdecurva, vertice longitrorsum percurrenter obsolete unicarinato, genis vix ad apicem protuberantiae productis, apicem versus sensim nonnihil angustatis, fronte tricarinata, carina media apicem versus evanescente, areis lateralibus apicem versus latioribus. Clypeus tricarinatus. Thorax et scutellum parallele tricarinata. Tibiae posticae quinque vel sex-spinosae (tibia sinistra exempli descripti spinis 6 , recta spinis 5 armata).

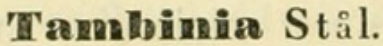

Corpus parvum. Caput thorace angustius, vertice producto, apice rotundato, reflexo-marginato, medio longitrorsum carinato; fronte valde reclinata, fere horizontali, inter et infra oculos parallela, supra oculos retrorsum subangustata, basi rotundata, latitudine plus dimidio longiore, marginibus subelevatis, medio longitrorsum carinata; clypeo triangulari, convexiusculo, utrimque haud carinato. Ocelli adsunt obsoleti mox infra oculos. Antennae breves, mox pone oculorum partem inferam sitae. Thorax medio anterius productus, postice profunde emarginatus, tricarinatus, carinis lateralibus obliquis. Scutellum tricarinatum, carinis lateralibus antrorsum convergentibus, media postice abbreviata, et per sulculum transversum terminata. Tegmina corpore circiter duplo longiora, subparal- 
lela, apice rotundata, corio posterius per seriem transversam venularum ad apicem clavi incipientem extrorsum et retrorsum oblique ductam bipartito, parte anteriore venis longitudinalibus 4 instructis, prima margini costali valde approximata, secunda posterius furcata, quarta prope basin tertiae incipiente, medio fere furcata; parte posteriore venis longitudinalibus 7 , ex parte pone medium furcatis, et (exterioribus exceptis) per venulas transversas semel conjunctis. Tibiae posticae infra medium bispinosae.

In vicinitate Monopsidis locandum insigne genus.

1. T. languida. Virescente -albida, vertice latitudine basali parum longiore; fronte latiludine vix duplo longiore, carina apicem versus evanescente; venulis transversis partis apicalis tegminum venas longitudinales ante harum medium conjungentibus, spinulis tibiarum tarsorumque posticorum apice fuscis. - Long. 4, Long. cum tegm. 8 Millim.

Patria: Ceylon. Mus. Berol.

2. T. debilis. Virescente-albida; vertice latitudine nonnihil breviore; fronte latitudine vix duplo longiore, carina percurrente; venulis transversis partis apicalis tegminum venas longitudinales pone harum medium conjungentibus, areolis antea-picalibus basi macula fuscescente notatis; spinulis tibiarum tarsorumque porticorum apice fuscis. - Long. 4, Long. cum tegm. 7 Millim.

Patria: Ceylon. Mus. Berol.

3. T. rufo-ornata. Sordide flavo-albida, tegminibus (versus costam apicemque exceptis) dilute flavo-virescentibus, maculis 2 parvis verticis thoracisque nec non lineolis 2 anticis approximatis scutelli sanguineis; vertice latitudine vix longiore; fronte latitudine dimidio fere longiore; venulis transversis partis apicalis tegminum venas longitudinales ante harum medium conjungentibus. Long. 4, Long. cum tegm. 7 Millim.

Patria: Ceylon. Mus. Berol.

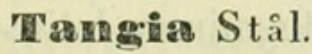

Caput ante oculos plus minus prominens, cum oculis thorace dimidio transverso nonnihil latius; vertice elevato-marginato, medio carina longitudinali; fronte marginibus leviter elevatis, medio percurrenter carinata; clypeo oblongo-triangulari, medio obsolete carinato. Ocelli adsunt mox infra oculos. Thorax late transversus, postice angulato - emarginatus, anterius medio rotundato-productus, tricarinatus, carinis lateralibus subarcuato-divergentibus. Scutellum thorace plus ter, fere quadruplo longius, tricarmatus, carinis latera- 
libus anterius nonnihil convergentibus. Tegmina abdomen tertia fere sua parte superantia, subparallela, parte tertia apicali per seriem transversam venularum a parte anteriore separata, area hac apicali sat dense venoso-reticulata, venis longitudinalibus compluribus per venulas numerosas transversas conjunctis instructa; parte anteriore corii vena intracostali a costa plus minus remota, venis 3 aliis longitudinalibus, prima apice, secunda nonnihil pone medium, tertia medio furcatis; area inter costam venamque intracostalem latitudine variabili, nunc transversim venosa, nunc absque venis transversis. Tibiae posticae trispinosae.

Monopsidi et Eutropisti (Schaum), illi praesertim affine genus.

* Area intracostali angusta, absque venulis transversis.

1. T. viridis Walker. Pallide subvirescente-flavescens; vertice latitudine sublongiore, apice semicirculariter rotundato, ante oculos sat longe prominente; fronte latitudine media plus duplo longiore, supra medium parallela, infra medium utrimque nonnihil ampliata. - Long. $5 \frac{1}{2}$, Long. cum tegm. 8 Millim.

Monopsis viridis Walk. List of Homopt. II. p. 325. 3. (descriptio Walkeri bene convenit.)

Patria: St. Thomas. Mus. Berol.

** Area intracostali tegminum latiore, venis transversis pluribus pone medium instructa.

2. T. Kraat zi. Pallide subvirescente-flavescẹns; vertice transverso, latitudine dimidio breviore, dimidia fere longitudine sua oculos superante, apice late rotundato; fronte latitudine media fere dimidio longiore, prope apicem utrimque ampliata, sursum sensim

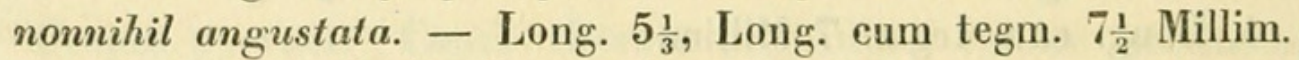

Patria: Insula St. Jean. Mus. Berol.

${ }^{* * *}$ Area intracostali tegminum latiuscula, venis transversis tota instructa.

3. T. Schaumi. Pallide flavescente-virescens; vertice transverso, longitudine duplo et dimidio latiore, apice latissime rotundato, ante oculos paullulum prominulo; fronte latitudine media vix dimidio longiore, prope apicem utrimque ampliaia, sursum sensim

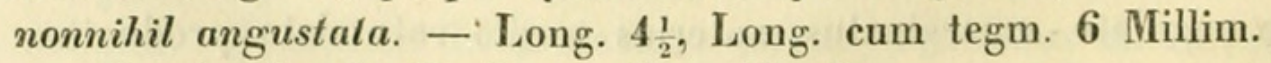

Patria: Insula St. Jean. Mus. Berol.

Obs. Tibia postica sinistra exempli descripti bispinosa. 


\section{Thadella Stil.}

Praecedenti valde affine genus, structura tegminum tantum diversum. Tegmina abdomen dimidia fere longitudine sua superantia, a medio basin versus leviter angustata, latitudine media duplo et dimidio fere longiora, area intracostali latiuscula, transversim venosa; corio nonnihil pone medium per seriem transversam antrorsum arcuatam venularum diviso, parte apicali venis longitudinalibus compluribus, per venulas transversas conjunctis instructa; parte anteriore venis longitudinalibus lateralibus fere a medio, media pone medium furcatis.

1. L. pallida Walker. Pallide testaceo- vel subvirescenteflavescens; vertice transverso, longitudine fere dimidio latiore, ante oculos prominente, apice late rotundato; fronte latitudine media fere duplo longiore, infra medium utrimque nonnihil ampliata. - Long.

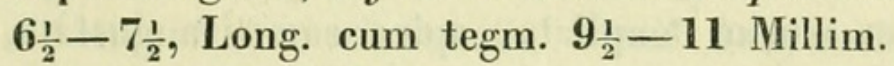

Monopsis pallida Walk. List of Homopt. II. p. 325. 2. (descriptio Walkeri sat bene convenit.)

Patria: Porto Rico. Mus. Berol.

\section{Crastroinhia Stål.}

Corpus ovale, subdepressum. Caput cum oculis thorace fere $\frac{1}{3}$ angustius; vertice parallelo, antice prominulo, rotundato-subangulato, absque carina media; fronte plana, latitudine longiore, a basi ultra medium sensim levissime ampliata, ante medium utrimque carina basin versus cum opposita arcuato-convergente, et confluente; clypeo tricarinato. Ocelli adsunt mox infra oculos. Thorax scutellumque planiuscula, obsoletius tricarinata, ille postice latissime sinuatus, scutello dimidio fere brevior. Tegmina parallela, abdomen parum superantia, apice oblique subtruncata, subcoriacea, venis longitudinalibus apicem versus per venulas transversas irregulares minus numerosas irregulariter reticulato-conjunctis. Alae adsunt.

In vicinitate praecedentium locandum genus.

1. G. vaginata. Testaceo-virescens; macula sublaterali basali scutelli, fascia inaequali prope basin, fasciolaque abbreviata obliqua pone medium tegminum nigrofuscis; fronte latitudine dimidio longiore. - Long. 11, Long. cum tegm. 15 Millim.

Patria: Bahia. Mus. Berol.

Feminae vagina longa, subarcuata, abdomini subaequilonga. 
Elioliptera Spin. (Helicoptera Am. et Serv.)

1. E. parnassia. Livida, supra fusco-irrorata et sparsa; ventre fusco; vertice ovali, medio carinato; fronte latitudine subapicali vix dimidio longiore. - Long. $7 \frac{1}{2}$, Long. cum tegm. $10 \frac{1}{2}$ Millim.

Patria: Graecia, Parnassus. D. Krüper. Mus. Berol.

Vertex percurrenter distincte carinatus, latidudine dimidio longior. Frons carina percurrente. Genae pallidae, ante oculos fuscoirroratae. Clypeus carina media obsoleta. Tibiae posticae nonnihil infra medium unispinosae.

\section{Chromelore $\mathrm{S} t \mathrm{a}$.}

Caput supra et ante oculos compresso productum et elevalum; vertice angusto, longo, marginibus lateralibus carinaque media foliaceo-elevatis; fronte et vertice confusis, illa basi angusta, dein apicem versus ultra medium sensim ampliata, apice rursus angustata, marginibus acutis, carina media percurrente; clypeo medio carina instructo, marginibus lateralibus elevatis, margines frontis continuatibus. Ocelli mox infra oculos siti. Thorax brevissimus, angulatus, tricarinatus, carinis lateralibus altissimis, divergentibus. Thorax obsolete tricarinalus. Tegmina abdomen multo superantia, apice involventia, venis longitudinalibus posterius per series 2 venularum transversarum conjunctis. Tibiae posticae supra medium unispinosae.

Elidipterae affine genus, capitis structura distinctissimum.

1. C. pallifrons. Supra nigra, subtus cum pedibus flavoalbida, ventre fusco, incisuris pallidis; parte scutelli apicali anterius triangulariler producta, maculis 2 clavi, una subbasali, postice biincisa, altera apicali, nec non macula parva subapicali aliaque majore costali pone medium corii pure flavis, hac per lineas 2 transversas nigris divisa. - Long. $4 \frac{1}{3}$, Long. cum tegm. 6 Millim.

Patria: Ceylon. Mus. Berol.

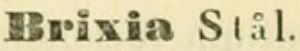

(Öfv. of k. Vet. Ak. Förg. 1856. p. 162.)

1. B. subfasciata. Testaceo-albida, genis supra oculos et infra antennas, vertice scutelloque infuscatis; tegminum venis fuscopunctatis, clavi fascia media, corii fascia ante medium nebulisque apicalibus fuscis, fasciis nigro-marginatis, vitta abbreviata corii basali ad suturam clavi, lineola transversa marginali anteriore, macula minuta marginali nonnihil pone medium maculisque irregula- 
ribus prope apicem nigro-fuscis. - Long. 6, Long. cum tegm. 9 Millim.

Patria: Ceylon. Mus. Berol.

Vertex antrorsum angustatus, antice truncatus, marginibus lateralibus valde elevatis, latitudine nonnibil longior. Frons valde elongata, basin versus angustata, basi truncata, marginibus dilatatis, dimidio apicali carina obtusa distincta instructo. Clypeus marginibus acutis, subdilatatis, medio carinatus. Scutellum tricarinatum, carinis lateralibus retrorsum divergentibus.

\section{FPđollerias Stål.}

Corpus leviter compressum. Caput truncatum, vertice transverso, apice truncato, marginibus lateralibus leviter elevatis, medio carinato, ante oculos parum prominente; fronte concaviuscula, basin versus angustata, supra clypeum utrimque leviter ampliata, medio percurrenter carinata, marginibus dilatatis; clypeo tricarinato. Oculi subtus subsinuati. Ocelli duo, mox infra partem anticam oculorum siti. Thorax quam brevissimus, angulato-arcuatus. Scutellum convexum, maximum, parallele tricarinatum, parte discoidali carinata plana. Tegmina abdomine plus duplo longiora, apicem versus sensim latiora, apice rotundato - truncata, venis longitudinalibus 3 principalibus, media medio fere, lateralibus longius ante medium furcatis, apicem versus per seriem venularum transversarum conjunctis. Pedes breviusculi, tibiis posticis inermibus, articulo tarsorum posticorum primo 2 apicalibus ad unum dimidio longiore.

Brixiae affine genus.

1. P. arcuigera. Testaceo-albida; lateribus scutelli, corii maculis raris parvis sparsis, arcuque subangulato magno pone medium latitudinem tegminis totam occupante, intus convexo, dorso abdominis (exceptis incisuris), fasciis lateralibus angustis clypei, maculis parvis basali et apicali femorum annulisque basali et apicali tibiarum anteriorum fuscis. - Long. $3 \frac{3}{4}$, Long. cum. tegm. 6 Millim.

Patria: Ceylon. Mus. Berol.

\section{'Thionia Stål.}

Corpus oblongum, crassum. Caput ante oculos haud prominens, truncatum; vertice transverso; fronte latitudine plus minus longiore, basin versus subangustata, carina longitudinali supra medium carinaque utrimque apicem haud attingente, basi arcuata et cum opposita conjuncta; clypeo convexo. Ocelli adsunt. Tegmina 
abdomen superantia, retrorsum angustata, oblongo obovata, venis longitudinalibus distinctis, venis transversis rarioribus, obsoletis (posterioribus distinctioribus) conjunctis. Alae adsunt. Tibiae posticae bispinosae.

Genus Colpopterae affine, corpore crasso, scutello thorace parum longiore, plano, tegminibus parcius, obsoletius minusque regulariter transversim venosis.

Huc pertinent Issi longipennis (Spin.) et cinctifrons (Stål) nec non plures aliae affines species.

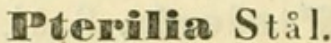

Corpus ovale, crassum. Caput cum oculis thorace nonnihil angustius, ante oculos vix prominulum, vertice transverso, utrimque subcarinato-elevato; fronte ovali, basi profunde sinuato, carinis longitudinalibus 3 instructa, basi arearum lateralium producta; clypeo convexo. Ocelli desunt. Thorax transversus, parte media antica inter oculos retrorsum prominentes valde producta. Scutellum thoraci aequilongum, planum. Tegmina vix tectiformia, abdomen parum superantia obovata, distincte venosa, pone medium irregulariter reticulata, subcoriacea, area costali membranacea, angusta, basin versus angustissima, transversim venosa, erosula, apice obtuse angulatoproducta. Alae adsunt. Tibiae posticae bispinosae.

Isso affine insigne genus.

1.P. ceylonensis. Dilute griseo-virescens, fuscovaria; annulis pedum discoque ventris nigris; tegminibus testaceis, virescentevenosis, clavo interdum virescente, area costali membranacea sordide pellucida. - Long. 10-12 Millim.

Patria: Ceylon. Mus. Berol.

\section{Eugandila $S$ tål.}

Corpus compressum. Caput productum; vertice transverso; fronte valde producta, conica, apice fissa. Ocelli nulli. Thorax scutellumque plana, hoc illo nonnihil longius. Elytra pendentia, oblique subtriangularia, ad commisuram conjunctim concaviuscula, apice lata, oblique truncata, coriacea, parce reticulata. Tibiae posticae bispinosae.

Amphiscepae affine genus, forma capitis distinctissimum.

1. L. fissiceps. Sordide pallide flavescens, fusco-virorata; genis, frontis sinu, pedibusque anterioribus fuscis, minute pallidoirroratis; coxis trochanteribusque anterioribus albis, coxis mediis 
basi nigro-fuscis; tegminibus granulatis, fusco-maculatis. - Long. $6 \frac{1}{2}$, Long. cum tegm. vix 7 Millim.

Patria: Ceylon. Mus. Berol.

\section{Caliscelis Lap.}

1. C. eximia. Pallide flavo-grisea, fronte planiuscula, antrorsum parum producta, infra oculos leviter angustata, latitudine longiore, tricarinata, carinis lateralibus percurrentibus, basin versus subconvergentibus; thorace carina mêdia instructo, scutello plus dimidio breviore. 우. $\sigma$.

ऽ. Fronte latitudine media tertia fere parte longiore, carina media percurrente; parte costali tegminum, corporis vitta lata utrim. que laterali pedibusque anticis nigris, horum femoribus subtus, tibiis utrimque (extus magis quam intus) rotundato-dilatatis. - Long. $3 \frac{1}{3}$, Lat. $1 \frac{1}{4}$ Millim.

ㅇ. major, unicolor, fusco-irrorata; fronte latitudine quarta parte longiore; femoribus anticis subtus, tibiis anticis utrimque (quam apud marem minus) modice dilatatis. Long. 4, Lat. $1 \frac{1}{2}$ Millim.

Patria: Ceylon. Mus. Berol.

\section{Nubithia Stål.}

Corpus compressum. Caput ante oculos parum prominens, vertice subquadrato, postice sinuato, antice rotundato, concaviusculo, carina media instructo; fronte oblonga, sursum sensim angustata, levissime convexa, marginibus vix elevatis, carina media percurrente; clypeo convexo, medio carinato. Ocelli nulli. Thorax basi truncatus, anterius medio inter oculos retrorsum valde prominulos rotundato-productus. Scutellum thorace nonnihil longius, carinis 2 retrorsum divergentibus instructum, inter carinas planum. Tegmina abbreviata, parum ultra medium abdominis extensa, parallela, apice rotundata, irregulariter reticulato-venosa, tectiformia, ad commisuram conjunctim leviter depressa. Alae nullae. Pedes mediocres; tibiis posticis trispinosis.

Hysteroptero affine genus.

1. N. grisescens. Flavescente-grisea; fronte latitudine media fere duplo longiore, ad margines laterales granulis minutis pallidis instructa; thorace scutellique lateribus pallido-granulatis; cellulis apicali-marginalibus tegminum anguste fusco-marginatis. Long. 4, Lat. $1 \frac{1}{2}$ Millim.

Patria: Cassapava. Mus. Berol.

Berl. Entom. Zeitschr. III. 


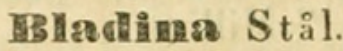

Caput ante oculos parum prominens; vertice transverso, postice sinuato; fronte plana, quadrata, marginibus lateralibus acutis, subreflexis, carina media percurrente, utrimque serie tuberculorum obsoletorum deplanatorum, basin versus cum opposita convergente, instructa; clypeo medio distincte carinato. Thorax antice rotundatoproduclus, postice late sinuatus, medio carinalus. Scutellum transversim convexum, parallele tricarinatum, parte carinata plana. Tegmina parallela, acufe tectiformia, postice compressa, apice oblique truncata, angulis apicalibus rotundata; venis longitudinalibus distinctis, parte tertia apicali distincle, reliqua minus distincte, irregularius reticulato-venosa, area costali transversim venosa angusta. Tibiae posticae quadrispinosae.

Prope Ricaniam locandum genus.

1. B. fusco-venosa. Fusco-teslacea, subtus cum pedibus, scutelli carinis thoraceque pallidior, hoc fusco-irrorato; tegminibus dilute fuscescente-hyalinis, fusco-venosis; fronte latitudini subaequilonga, sursum leviter angustata. - Long. 7, Long. cum tegm. 12 Millim.

Patria: Columbia. Mus. Berol.

Plures huc pertinent species mihi cognitae.

\section{Stacota Stål.}

Caput thorace nonnihil angustius, ante oculos nonnilil prominens; vertice quadrato, longitudine vix latiore, marginibus leviter elevatis, medio carinato; fronte oblonga, sursum sensim angustata, marginibus leviter reflexis, medio pereurrenter carinata; clypeo medio distincte, basi utrimque valde obsolete carinato. Ocelli adsunt. Antennae breves, cylindricae. Thorax antice angulato-rotundato-productus, postice late emarginatus, medio carinatus. Scutellum parallele tricarinatum, carinis lateralibus anterius leviter convergentibus, haud confluentibus, parte carinata planiuscula. Tegmina ampla, abdomen vix dimidia sua longitudine superantia, apicem versus sensim latiora, apice late rotundata, corio venis 3 longitudinalibus, prima (a clavo) ante medium tegminis furcala, nonnihil pone medium per venulas transversas arcuatas, venas longitudinales retrorsum emittentes, conjunctis, his etiam venis longitudinalibus longius apicem versus per seriem transversam venularum conjunctis. Tibiae posticae trispinosae. 
1. S. comptella. Dilute viridis; capitis thoracisque carinis dilute ferrugineis; venis tegminum vitreorum setulosis; macula ulrimque parva pectoris nigra; fronte lalitudine media vix duplo longiore. - Long. 6, Exp. tegm. 16 Millim.

Patria: Ceylon. Mus. Berol.

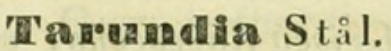

Caput thorace paullo angustius, ante oculos parum prominens, obtusum; vertice transverso, postice late sinuato, marginibus leviter elevatis; fronte subquadrata, sursum leviter angustata, supra clypeum subito valde rotundato - angustata, carinis 3, media percurrente, distincta, lateralibus obsoletis, abbreviatis; clypeo medio carinato. Ocelli adsunt. Thorax arcuatus, antice rolundatus, postice latiuscule sinuatus, medio carinatus. Scutellum anterius convexiusculum, tricarinatum, carinis lateralibus anterius arcuato-convergentibus et conjunctis. Tegmina ampla, retrorsum multo latiora, apice oblique late rotundata, vitrea, corio venis 3 longitudinalibus, longe ante medium furcatis, disco per venulas rariores transversas irregulariter conjunctis, apicem versus denique per series 2 transversas venularum magis regulares conjunctis, area costali latiuscula, venis compluribus transversis instructa. Tibiae posticae trispinosae.

Huc pertinet Ricania servillei (Spin.) ex Isle de France. In Museo Holmiensi adest affinis species ex insula quadam in vicinitate Javae.

\section{Seolypopa Stå.}

Caput thoraci subaequilatum, truncatum, ante oculos haud vel vix prominens; vertice transverso, postice late sinuato; fronte trans versa, a medio sursum parum, versus clypeum valde rotundato-angustata, marginibus vix reflexis, tricarinata, carinis media distincta, lateralibus abbreviatis, obsoletis; clypeo convexo, haud carinato. Ocelli adsunt. Thorax semilunatus, antice rotundatus, postice late sinuatus, medio carinatus. Scutellum tricarinatum, carinis lateralibus anterius convergentibus. Tegmina sat ampla, abdomen nonnihil superantia, apicem versus sensim latiora, apice oblique truncata, angulo apicali exteriore rotundato; corio venis longitudinalibus, prope basin furcatis, per series 3 venularum transversarum conjunctis; area costali venis transversis instructa. Tibiae posticae bispinosae.

1. S. urbana. Fusco-testacea; vitta tegminum intramarginali, ultra medium extensa, pone medium marginem attingente (et 
ibidem macula albida notata), pone hanc maculam introrsum irregulariter dilatata, maculisque nonnullis parvis ad suturam clavi nigro-fuscis, limbo lato apicali fuscescente, pallido-irrorato. - Long. 7, Exp. tegm. 19 Millim.

Patria: Sidney. Mus. Berol.

2. S. scutata. Griseo-flavescens, supra fusco-testacea, scutello nigro; tegminibus fuscis, pallido-irroratis, area costali, macula transversa obliqua costali subapicali, vitta subapicali maculaque api-

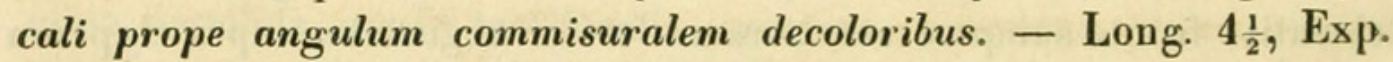
tegm. 13 Millim.

Patria: Nova Hollandia. Mus. Berol.

\section{Nogodiuna Stíl.}

Caput ante oculos nonnihil prominens, thorace paullo angustius; vertice transverso, postice late sinuato; fronte latitudine longiore, leviter reflexo-marginata, carinata; clypeo tricarinato. Thorax antice rotundato-productus, postice late sinuatus. Scutellum tricarinatum, carinis lateralibus antice convergentibus. Tegmina ampla, apicem versus nonnihil latiora, corio venis 3 primariis, furcatis, disco per venulas transversas rariores irregulariter conjunctis, pone medium per series (unam saltem) venularum transversarum regulares conjunctis; area costali venis numerosis transversis. Tibiae posticae quadrispinosae.

Huc pertinent Ricania reticulata Fabr. et nonnullae aliae.

\section{Pyrilla Stål.}

Caput longissime protuberans; vertice vix dimidiam parlem protuberantiae occupante, parallela, utrimque leviter carinato; genis vertici aequilongis; fronte longissima, longitrorsum bicarinata, carinis percurrentibus, apice coëuntibus, areis media parallela, lateralibus a clypeo ad medium parallelis, dein dilatatis et partem lateralem et supero-anteriorem protuberantiae formantibus, superne per carinam nullam separatis, confusis. Ocelli adsunt. Thorax capite cum oculis dimidio latior, basi truncatus, cum scutello subparallele tricarinatus. Tegmina tectiformia, parallela, latitudine fere ter latiora, venis longitudinalibus pone medium furcatis, per series 4 transversas venularum magis obsoletarum conjunctis; area costali sat dense transversim venosa. Tibiae anticae subcompressae, posticae bispinosae.

Lophopi affine genus. 
1. P. protuberans. Sordide testaceo-flavescens, tegminibus apicem versus nigro-sparsis. - Long. 11, Long. cum tegm. 16 Millim.

Patria: Java. Mus. Berol.

\section{Dididectus Kirby.}

1. O. Schönherri. Fusco-testaceus; clypeo, pectore, pedibusque pallidis; abdomine fusco-roseo; tegminibus glauco-fuscescentibus, dilute sanguineo-venosis, apice minute albo-maculatis, ante medium costae maculis nonnullis minutis verticeque albo-mucoreis. - Long. $5 \frac{1}{2}$, Long. cum tegm. $10 \frac{1}{2}$ Millim.

Patria: Puerto Rico. Mus. Berol.

Caput thoraci scutelloque ad unum nonnihil longius, vertice parallelo, basi leviter dilatato, concavo; fronte valde compressa, marginibus lateralibus apice et prope basin contiguis; genis magnis, antrorsum sensim parum angustatis. Antennae fuscae, appendicibus longis.

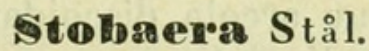

Caput thorace nonnihil angustius, truncatum; vertice transverso; fronte elongala, subparallela, marginibus carinatis, medio carina percurrente, basi ipsa furcata instructa; genis obliquis, triangularibus, haud parallelis; clypeo tricarinato. Antennae compressae, capiti transverso cum oculis vix aequilongae, articulo ultimo penultimo longiore. Thorax brevis, postice late emarginatus, tricarinatus, carinis lateralibus posterius leviter divergentibus. Tegmina abdomen multo superantia. Tibiae posticae bispinosae.

Amblycoti affine genus.

1. S. concinna. Fusco-testacea ( $\left.\sigma^{\top}\right)$, vel pallida (ㅇ); fascia lata frontis genarumque, maculis marginalibus abdominis parvis, pedibusque pallidis, his nigro-annulatis; tegminibus vitreis, fascia obliqua ante medium, fasciis 2 opposite obliquis, una mox pone medium, altera prope apicem, ad commisuram conjunctis, fuscis; venis

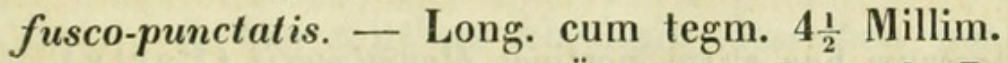

Delphax concinna Stål Öfv. af K. Vet. Ak. Förh. 1854.

Patria: Mexico. Mus. Berol.

Adest in Museo Berolinensi species e Pensylvania S. concinnae maxime affinis et similis. 


\section{$2 \mathrm{BHL}$ Biodiversity Heritage Library}

Stål, Carl. 1859. "Novae quaedem Fulgorinorum formae speciesque insigniores." Berliner entomologische Zeitschrift / herausgegeben von dem Entomologischen Vereine in Berlin 3, 313-327. https://doi.org/10.1002/mmnd.18590030405.

View This Item Online: https://www.biodiversitylibrary.org/item/36385

DOI: https://doi.org/10.1002/mmnd.18590030405

Permalink: https://www.biodiversitylibrary.org/partpdf/9194

\section{Holding Institution}

Smithsonian Libraries

\section{Sponsored by}

Smithsonian

\section{Copyright \& Reuse}

Copyright Status: Public domain. The BHL considers that this work is no longer under copyright protection.

This document was created from content at the Biodiversity Heritage Library, the world's largest open access digital library for biodiversity literature and archives. Visit BHL at https://www.biodiversitylibrary.org. 